\title{
Z Research Square \\ Impact of COVID-19 on selected criminal activities in Dhaka, Bangladesh
}

Sungida Rashid, Ph.D. ( $\square$ sungida.rashid@siu.edu )

Sothern Illinois University Carbondale https://orcid.org/0000-0002-7487-243X

Research Article

Keywords: COVID-19, Crime trend analysis, ARIMA forecast, Bangladesh

Posted Date: November 3rd, 2020

DOI: https://doi.org/10.21203/rs.3.rs-100169/v1

License: (9) (i) This work is licensed under a Creative Commons Attribution 4.0 International License. Read Full License

Version of Record: A version of this preprint was published at Asian Journal of Criminology on November 3rd, 2020. See the published version at https://doi.org/10.1007/s11417-020-09341-0. 


\section{Abstract}

The COVID-19 pandemic has made a substantial impact on the historical criminal trend of the world. Using Dhaka Metropolitan Police (DMP) recorded open crime data of the total number of arrests, this article aims to understand how the frequency of selected crime trends has changed during the pandemic in Dhaka city, the capital of Bangladesh. Time-series forecasting models ARIMA (Auto Regressive Moving Average Model) are used to forecast the expected frequency of arrests in different crime types in 2020 in the absence of the pandemic. Forecasting techniques are applied to estimate sixmonth-ahead forecasts of the total number of arrests of arms dealing, vehicle theft, and illegal drug trafficking. The actual and predicted numbers of total arrests for vehicle thefts are decreased during pandemic while actual arrests in illegal drug trafficking show a steep upward trend- around $75 \%$ more than that of the expected frequencies. Estimated results are used to recognize scopes and suggestions for future research on the relationship between crimes and pandemic.

\section{Introduction}

After the first case of COVID-19 disease reported in Wuhan, China on December 31, 2019, the pandemic has spread over the world and quickly became a global crisis. As of October 14, 2020, the World Health Organization (WHO) Coronavirus Disease (COVID-19) Dashboard reported 38,002,699 confirmed cases including 1,083,234 deaths worldwide (WHO, 2020). To combat the pandemic an unprecedented shift in the social structure i.e. global lockdown took place; people are advised to wash their hands and stay at home, travels are restricted, a new phenomenon known as work from home is introduced.

While the primary focus of the stay-at-home order was to confine the pandemic might impose a significant impact on other socio-economic factors e.g. stagnating economic growth. Another prominent effect of any exceptional events like natural disasters or pandemic can be an upsurge of illicit activities (Cohen \& Felson, 1978). Several explanations can be suggested for this shift in criminal behavior, but the most prominent one is the change in the opportunity structure (Hodgkinson \& Andresen, 2020). For example, if people are staying at home and restricting their movements, offenses like burglaries are supposed to drop (Campedelli, Aziani, \& Favarin, 2020). But new targets or victims may emerge aka cybercrimes as work and life have now shifted online (Lallie, et al., 2020). Crime types like violent crime may increase (e.g. domestic violence, intimate partner violence) as the offenders and victims are homebound for longer periods of time whereas robbery, serious assault types of crimes may decrease (Bullinger, Carr, \& Packham, 2020; Pearson, 2020) as people are unable to converge similarly as before.

Bangladesh began its complete lockdown on March 26 after the first case was officially reported on March 8, 2020. After more than 2 months of the official stay-at-home order, the government of Bangladesh announced that from May 31, 2020, there will be an easing in the COVID-19 official lockdown (Government of Bangladesh, 2020). This study tries to shed a light on the criminal behavior across crime types in Dhaka, Bangladesh during the official lockdown period. Most literature focuses on the relationship between pandemic and crime are done from a developed country perspective and established variant outcomes. Only a handful of studies are done to explore the effect of the pandemic on the overall crime trend but most of those are a compilation of media reports (Ahmed, Khaium, \& Tazmeem, 2020; Bhuiyan, Sakib, Pakpour, Griffiths, \& Mamun, 2020). One probable reason could be, least developed and developing countries still suffer from the unavailability of authentic and updated crime data sources (UNODC, Global Study on Homicide, 2019). This creates an opportunity to explore the effects of this lockdown on crime from the context of an emerging economy. This paper tries to bridge the knowledge gap by analyzing crime trends during the pandemic in Dhaka, the capital of Bangladesh.

Here monthly incidence reports of Dhaka Metropolitan Police (DMP) are used to create time-series data of the total number of arrests for three (03) types of offenses: guns \& ammunitions, vehicle theft, and illegal drugs trafficking. Using monthly data for each series range from January 2012 to September 2020 , this paper tries to estimate what would be the total arrest counts for each crime series without the pandemic and how that fluctuate during and after the official lockdown order. This is the first empirical analysis on Bangladesh of the extent to which crime has changed during the COVID-19 pandemic.

\section{Background}

Media outlets all over the world have been screaming out on the potential upsurge of various crime types due to coronavirus. With the media activists, and the academics are also weighing in with their predictions. There has been significant evidence of potential crime hike around the world associated with COVID 19 and the ensuing stay-at-home orders. Theoretically, there are several mechanisms through which lockdown initiatives are likely to influence criminal offenses. The most common one is the vigorous disruption of people's daily routine, which may significantly alter financial conditions provoking crime to occur. The effective stay-at-home regimes may also have a significant downward effect on certain crime types e.g. burglary. On the other hand, this could enhance the volume of domestic or intimate partner violence, which thrives behind closed doors (Piquero, et al., 2020; Deluca, Mitchell, Papageorge, \& Coleman, 2020).

Family violence with adolescence may also rise significantly as the schools are closed for a substantial period now. Both parents and teens living under the same roof for an extended period may increase contacts between young people who use violence and their parents. Putting a greater risk of domestic violence with increasing social isolation, limited opportunities to seek help from family and friends. (Pearson, 2020; Usher, Bhullar, Durkin, Gyamfi, \& Jackson, 2020).

The literature on the impact of COVID 19 on the overall crime pattern is limited because of the obvious-the phenomenon that is still new. The closest work to this article is the recent work investigating the variation in crime patterns using time series analysis (Ashby, 2020). Using historical data of 16 US cities, the author showed that even though city-weeks crime diverges significantly from historical averages, but most crime changes were not statistically significant. However, (Abrams, 2020) investigated the before and after effect of stay at home (SAH) order on different crime types. The article found a 
significant drop in violent and property crimes before the SAH order in 25 cities in the US. There was also substantial variation in the overall plummet of crime rates across cities.

\section{Methodology}

\subsection{Data}

Dhaka, the capital of Bangladesh, is the area of interest for this study. According to the United Nations - World Population Prospects, the current metro area population of Dhaka in 2020 is $21,006,000$. This makes it the sixth-most densely populated city in the world. Public safety in Dhaka is maintained by Dhaka Metropolitan Police (DMP) with 50 stations and more than 34,000 personnel (Rabbi, 2018). Like any other densely populated megacity, Dhaka city has experienced its fair share of diverse criminal activities. Depending on the period and crime type- the total crime rate of Dhaka city fluctuates either upward or downward. This paper uses administrative monthly crime data published by DMP. Dhaka is chosen in this study because of the availability of recent crime data. Each month DMP provides a publicly accessible incident-level extract of police-records for different offense types[1]. This open-access data source allows monitoring of emerging crime trends which would be obscured in annual crime statistics bulletins produced by the government and other independent agencies.

The DMP mandates officers to record daily criminal activities along with crime types, detailed descriptions of the act (e.g. different types and number of guns and ammunition seized), number of total suspects, and number of total arrests. At the month-end, DMP crime analysts upload monthly crime statistics on their website[2]. The DMP reports different types of crimes such as dacoit, burglary, homicide, guns \& ammunition, drugs, women \& child repression, kidnapping, theft, and other types of offenses. But this paper mainly focused on three (03) types of incidents; guns \& ammunitions, vehicle thefts, and drugs[3].

To create monthly time-series data, the total number of arrests for each of the three crimes were collected from DMP's monthly incidence reports. The complete dataset consists of the total number of arrests for guns \& ammunitions, vehicle thefts, and illegal drug trafficking from January 2012 to September 2020, where the total observation number, $\mathrm{N}=102$. In Table 1, descriptive statistics for the total number of arrests for the individual categories are displayed. Despite the limitations of open data sources, articles on crime literature were found to rely on them to assess the periodic crime trend (Ashby, 2020). To understand the pattern and trend of the raw data, a simple linear trend analysis is performed without considering the lockdown effect due to COVID-19. The visual representation of the inherent trends of the series can be found in Figure 1. At the beginning of the analysis, a simple linear trend will help to understand the inherent trend of the raw data. Simple linear trends display a sharp plummet in vehicle theft and a steady increase in the arrest incidents for drugs. Arrest cases for guns and ammunitions seem to have a slight downward slope.

Table 1: Descriptive Statistics

\begin{tabular}{|llllll|}
\hline Variable & Obs. & Mean & Std. Dev. & Min & Max \\
\hline Guns \& Ammunitions & 102 & 51.7188 & 39.703 & 5 & 280 \\
Vehicle theft & 102 & 41.8812 & 28.47 & 3 & 111 \\
\hline Drugs trafficking & 102 & 1214.27 & 652.795 & 161 & 2616 \\
\hline
\end{tabular}

Data source: DMP website and author's compilation

\subsection{Econometric Approach}

To understand the actual impact of COVID 19 on the overall crime scenario, some estimates of the crime trend that would occur without the pandemic are needed. If the number of criminal offenses in absence of COVID is estimated, it can be compared with that of the actual number. The results can then identify whether the pandemic has intensified the overall crime trend or not. In the quest for a suitable forecasting model, this paper operationalizes an Auto Regressive Moving Average (ARIMA) model for each of the three criminal offense categories. ARIMA models are a particular type of time series forecasting technique where AR indicates the own lagged values of regressed variables and MA is the linear combination of error terms at various times in the past (Enders, 1995). The accuracy of future predictions substantially depends on the strength of past and future relationships among variables.

For each crime type, the observed values after March 2020 are excluded from the estimation process as from March 26, 2020, the official lockdown was implemented in Bangladesh. To implement ARIMA, each series need a statistical assessment of the presence of a unit-root or non-stationarity. The Augmented Dickey-Fuller (ADF) test is used to identify the stationarity of each series. The results of the ADF and Phillips-Perron test are given in Appendix (A 1). The series is used at the level if the unit-root test indicated stationarity. The next step is to specify the appropriate parameters of AutoRegressive (AR) and Moving Average (MA), each of the series is examined using Auto-Correlation (AC) and Partial Auto-Correlation (PAC) plot. The goal is to find the parsimonious and best-fitted model. Akaike Information Criteria (AIC) and Bayesian Information Criteria (BIC) are simultaneously considered for each model of each series. The lowest value of AIC and BIC indicates the best fit (Enders, 1995). The process of finding the final model is described in Table A 2. 
[1] Monthly reports are available for different years starting from 2012 to September 2020. Interested individual can freely download data from: https://dmp.gov.bd/crime_data_year/2020/.

[2] The DMP monthly crime reports are open for general use. But for most of the time the reports are written in Bengali, the local language of Bangladesh.

[3] The paper considers only three (03) crimes as the DMP's monthly incident reports are always incorporated crime statistics of these three types of offenses. In some months, DMP reported other crimes such as burglary, women and \& child repression, and others. But those are no consistent over the year.

\section{Results And Discussions}

Figures 1, 2, and 3 show the observed frequency of each crime type and their corresponding forecast frequency based on the ARIMA model (panel a). In panel $b$ of each figure, the model forecast with the associated $95 \%$ confidence interval is shown as a dashed line. Also shown on each figure is the date of the first day of official lockdown that took place due to COVID-19 in Dhaka, Bangladesh (which marks the end of the data with which the forecasts were made), together with the date on which the Government Bangladesh officially eased the stay-at-home order. The figures include the observed frequency of crime up to September 2020 inclusive, the most-recent available data at the time of writing.

Before engaging in a discussion of the individual crime pattern, some important features of these graphs need to be identified. For each series, predicted point estimation and prediction interval are based on the data before March 26, 2020, in the graph identified as "L". The final ARIMA specifications are used to forecast both point estimates and mean square errors (MSE). The MSE is used to calculate $95 \%$ confidence intervals from March 2020 up to and including September 2020 (panel b). For each series, a reference line "E" is added as an indication of May 31, 2020- officially easing of lockdown order.

\section{Guns \& Ammunitions}

Figure 2 shows that the frequency of arrests under illegal arms dealings was below (panel a) that of estimated by final model ARIMA $(0,0,1)$, but in no cases, the frequencies were consistently outside the $95 \%$ confidence interval of the model (panel b). This suggests the observed variation was within what would be expected based on the frequency of arms dealings in previous years. A sharp drop in the frequencies of both actual and forecasted are visible after stay-at-home order (L). But arrest cases seem to catch up after the restriction was eased (E). Overall, the frequency of serious assaults appears not to have systematically different between the actual and the forecasted ones. Theoretically, the results are quite expected, given the number of times people staying outside decreased substantially during the pandemic. So, incidents in illegal arms handling seem to coincide with the daily movement of people.

\section{Vehicle Theft}

Figure 3 shows that the frequency of thefts of motor vehicles had divergent patterns across Dhaka city. The arrests frequency of thefts from vehicles shows significant reduction and decreases were particularly large: between March 26 and May 31. The major cause of the decrease in vehicle theft is likely to be the unavailability of unattended vehicles to steal or steal

from during pandemic lockdown. The distribution of vehicles may have changed because the number of times people outside their homes or in public places decreased substantially. This significantly affected people's requirement to use private vehicles. But after the government announcement of easement of restriction, the number of people outside increased drastically. So as to the frequency of arrests for vehicle theft. In Figure 3 (panel a), during the lockdown period, initially, the actual frequency was below the forecasted frequency. But in the later period, the actual frequencies were higher than the predicted one. Future research could therefore consider the driving cause of the changing distribution of vehicle thefts arrests cases.

Drugs

Figure 4 shows the frequency of the arrests of illicit drug transactions. Though there is a sudden drop at the beginning of the pandemic started in midFebruary and the lowest frequency is in April. But the number starts to increase around May and keeps hiking till mid-June. During this period, the forecasted frequency is lower than the actual frequency and it remains lower till the end of the study period.

The main driver can be after the lockdown was initiated, DMP strictly controlled general movements, putting a natural restriction on the illicit drug trade. United Nations Office on Drugs and Crime (UNODC) published reports citing the reason as a disruption in the supply chains of physical drug markets and the change of drug trafficking patterns and routes due to mobility restrictions, closed borders, and a decline in overall world trade (UNODC, 2020).

However, Figure 3 shows that, at least during the latter part of the mobility restriction order, there is a surge in arrest cases for illicit drug handling. After the government's easing on stay-at-home order (point, E), a very sharp increase in the arrests cases for illicit drug trafficking is observed. Surprisingly in July, total arrest cases were reported 2369 whereas the ARIMA model's prediction is 675 , around a $75 \%$ lower in the forecast. In the first few weeks of the pandemic, there was substantial concern among lawmakers and metropolitan police departments to make restriction orders effective. When the 
restriction was eased, the latent demand for drug usage spiked and matched with the historical trend (Appendix 1). Several print media outlets (both in Bangla \& English) reported because of transport restrictions during pandemic, small and big consignments of narcotics are being transported using hearses, relief trucks, courier services, and daily necessities vehicles (Islam, 2020; Mollah \& Saad, 2020). Future research in this area might usefully recognize the appropriate strategies to reduce illegal drug trafficking in Dhaka. The current findings should be validated against qualitative measures and successful approaches of other metropolitan cities in diminishing drug trafficking.

\subsection{Limitations}

As with any analysis, this paper is not without its limitations. Because crime series is created from compiling the monthly incidence reports of Dhaka Metropolitan Police (DMP), we are limited to only those type of criminal offenses that are recorded by the DMP. Moreover, the analysis covers Dhaka city only since the incidence reports during the pandemic period are available only in that area. Different offenses like serious assaults, homicide, burglary, vehicle theft, domestic violence, sexual violence, cybercrimes have found to have a significant impact due to COVID-19 (Bullinger, Carr, \& Packham, 2020; Mohler, et al., 2020; Hodgkinson \& Andresen, 2020; Ashby, 2020; Abrams, 2020). Due to the unavailability of the category-wise historical crime data, this paper considers only three crime types; guns \& ammunitions, vehicle theft, and illegal drugs.

Recent media reports in Bangladesh quoting a surge in suicide cases during the pandemic period (Bhuiyan, Sakib, Pakpour, Griffiths, \& Mamun, 2020). Moreover, a notable upward trend in domestic and sexual violence is reported in print media (Tithila, 2020). Unfortunately, this paper doesn't consider those offenses as the DMP incidence reports don't produce any periodic case histories for those types of offenses. In the future, extensive quantitative research for suicide and intimate partner violence cases needs to be conducted to validate the media claims.

\section{Conclusion}

This study presents one of the first analyses on Bangladesh of the extent to which crime has changed during the COVID-19 pandemic. Specifically, it applies an iterative univariate ARIMA framework to three crime types (guns \& ammunitions, vehicle theft, and illegal drugs trafficking) in Dhaka, Bangladesh. Using appropriate ARIMA specifications for each crime series potential spurious conclusions derived from simple week-to-week or year-onyear comparisons. The government of Bangladesh mandated an official lockdown on March 26 and eased it on May 31 . It is important to note that the results presented here are based on recorded arrest data for each crime. Forecast patterns of the number of arrests for each crime series are compared within and beyond this period.

Present research finds a significant drop in arrest cases in arms dealing and vehicle theft during the stay-at-home order period. But for the case of illegal drug trafficking, the numbers seem to climb up rapidly when the government eased the lockdown order. The actual total number of arrests in illegal drug trafficking significantly overpowered the predicted ones- around $75 \%$. One worthy option could be because of movement restrictions, the inherent longterm trend in narcotic trading was suppressed which hikes up right after the restriction was lessened. Another important evidence on the surge of drug trading is identified in print media. During pandemic the law enforcement agencies were busy tackling the coronavirus situation, drug dealers have seemingly taken advantage of the consequent reduction in regular monitoring (Mollah \& Saad, 2020). Drug traders were found to use unconventional modes of transports in trafficking as all public transport except freight and emergency services was closed e.g. hearses, relief trucks, courier services.

Regardless of several limitations, and succeeding directions for future research, the present study contributes to the literature on exceptional events and crime from the context of an emerging economy. But then again cautious measures need to be taken in treating these early data as a definitive test of the crime-response to COVID-19. Extensive future research will be able to understand the relationships between coronavirus and crime trends. However, these early findings can certainly guide and shape greater scopes of future research.

\section{Declarations}

Funding: No funding was received for this paper.

Conflict of Interest: I am reporting that I, Sungida Rashid is the sole contributor of this article. It is to specifically state that "No Competing interests are at stake and there is No Conflict of Interest" with other people or organizations that could inappropriately influence or bias the content of the paper.

\section{References}

Abrams, D. S. (2020). COVID and Crime: An Early Empirical Look. U of Penn, Inst for Law \& Econ Research Paper No. 20-49, Available at SSRN: https://ssrn.com/abstract=3674032 or http://d.

Ahmed, S., Khaium, M. O., \& Tazmeem, F. (2020). COVID-19 lockdown in India triggers a rapid rise in suicides due to the alcohol withdrawal symptoms: Evidence from media reports. International journal of social psychiatry, 66(8), 827-829.

Ashby, M. P. (2020). Initial evidence on the relationship between the coronavirus pandemic and crime in the United States. Crime Science 9, 1-16.

Bhuiyan, A. I., Sakib, N., Pakpour, A. H., Griffiths, M. D., \& Mamun, M. A. (2020). Bhuiyan, A. I., Sakib, N., Pakpour, A. H., Griffiths, M. D., \& Mamun, M. A. (2020). COVID-19-related suicides in Bangladesh due to lockdown and economic factors: case study evidence from media reports. International Journal of Mental Health and Addiction.

Page 5/11 
Bullinger, L. R., Carr, J. B., \& Packham, A. (2020). COVID-19 and Crime: Effects of Stay-at-Home Orders on Domestic Violence (No. w27667). National Bureau of Economic Research.

Campedelli, G. M., Aziani, A., \& Favarin, S. (2020). Exploring the effect of 2019-nCoV containment policies on crime: The case of los angeles. arXiv preprint arXiv:2003.11021.

Cohen, L. E., \& Felson, M. (1978). Social change and crime rate trends: A routine activity approach. American Sociological Review, 44(4), 588-608.

Cohen, S. (2002). Folk devils and moral panics: The creation of the mods and rockers. Psychology Press.

Deluca, S., Mitchell, B., Papageorge, N., \& Coleman, J. (2020). The unequal cost of social distancing. Johns Hopkins coronavirus resource Center, https://coronavirus.jhu.edu/from-our-experts/the-unequal-cost-of-social-distancing.

Enders, W. (1995). Applied Econometric Time Series. New York: JohnWiley \& Sons, Inc.

Government of Bangladesh, C. (2020). Fighting with coronavirus: press briefing of Cabinet Secretary. Dhaka:

https://cabinet.gov.bd/sites/default/files/files/cabinet.portal.gov.bd/notices/9abbd38f_f012_401c_a172_4654fc2ffada/corona\%20press\%20briefing.pdf.

Hodgkinson, T., \& Andresen, M. (2020). Show me a man or a woman alone and l'll show you a saint: Changes in the frequency of criminal incidents during the COVID-19 pandemic. ournal of criminal justice, 69, 101706.

Islam, N. (2020, June 24). During the coronation period, drugs were also transported in the hearse (in Bangla). Daily Prothom Alo, p. 6.

Lallie, H. S., Shepherd, L. A., Nurse, J. R., Erola, A., Epiphaniou, G., Maple, C., \& Bellekens, X. (2020). Cyber Security in the Age of COVID-19: A Timeline and Analysis of Cyber-Crime and Cyber-Attacks during the Pandemic. arXiv preprint arXiv:2006.11929.

Mohler, G., Bertozzi, A., Carter, J., Short, M., Sledge, D., Tita, G., . . Brantingham, P. (2020). Impact of social distancing during COVID-19 pandemic on crime in Los Angeles and Indianapolis. Journal of Criminal Justice, 101692.

Mollah, S., \& Saad, M. (2020, May 16). Lax Surveillance Amid Covid-19 Crisis: Narcos active again. The Daily Star. Dhaka, Bangladesh. Retrieved October 20, 2020, from https://www.thedailystar.net/backpage/news/lax-surveillance-amid-covid-19-crisis-narcos-active-again-1903033

Pearson, E. (2020, April 3). Family violence calls drop amid fears victims can't safely seek help while in lockdown. The age. https://www.theage.com.au/national/victoria/family-violence-calls-drop-amid-fears-victims-can-t-safely-seek-help-while-in-lockdown-20200401p54fzq.html.

Piquero, A., Riddell, J., Bishopp, S., Narvey, C., Reid, J., \& Piquero, N. (2020). Staying Home, Staying Safe? A Short-Term Analysis of COVID-19 on Dallas Domestic Violence. American Journal of Criminal Justice, 601-635.

Poggio, E. C., Kennedy, S. D., Chaiken, J. M., \& \& Carlson, K. E. (1985). Blueprint for the future of the Uniform Crime Reporting Program: Final report of the UCR study. US Department of Justice, Bureau of Justice Statistics, Federal Bureau of Investigation.

Rabbi, A. R. (2018, July 08). DMP opens 50th police station at Hatirjheel. Dhaka Tribune. Dhaka, Bangladesh. Retrieved October 20, 2020, from https://www.dhakatribune.com/bangladesh/dhaka/2018/07/08/dmp-opens-50th-police-station-at-hatirjheel

Tithila, K. K. (2020, June 10). MJF: 13,494 women, children faced domestic violence during Covid-19 lockdown. Dhaka Tribune. Dhaka, Bangladesh. Retrieved October 20, 2020, from https://www.dhakatribune.com/health/coronavirus/2020/06/10/mjf-13-494-women-children-faced-domestic-violenceduring-covid-19-lockdown

Tompson, L. J. (2014). UK open source crime data: Accuracy and possibilities for research. Cartography and Geographic Information Science, 42 (2), 97111.

UNODC. (2019). Global Study on Homicide. Viena: 2019.

UNODC. (2020). Covid-19 and the drug supply chain: from production and trafficking to use. United Nations Office On Drugs And Crime. https://www.unodchttps://www.unodc.org/documents/data-and-analysis/covid/Covid-19-and-drug-supply-chain-Mai2020.pdf.

Usher, K., Bhullar, N., Durkin, J., Gyamfi, N., \& Jackson, D. (2020). Family violence and COVID-19: Increased vulnerability and reduced options for support. International journal of mental health nursing.

WHO. (2020). Who coronavirus disease (covid-19) Dashboard. https://covid19.who.int/.

\section{Appendix}

\section{Appendix}


A 1: Unit Root Test

\begin{tabular}{|lllll|}
\hline & \multicolumn{2}{l}{ Augmented Dickey-Fuller Test } & \multicolumn{2}{l|}{ Phillips-Perron unit-root test } \\
\hline Variable (at level) & Intercept & Intercept \& Trend & Intercept & Intercept \& Trend \\
\hline Guns arrest & $-6.231(0.000)$ & $-6.567(0.000)$ & $-6.148(0.000)$ & $-6.410(0.000)$ \\
\hline Vehicle theft arrests & $-3.983(0.0015)$ & $-5.595(0.000)$ & $-3.715(0.0039)$ & $-5.394(0.000)$ \\
\hline Drugs arrests & $-2.701(0.0339)$ & $-3.985(0.0092)$ & $-2.522(0.1002)$ & $-3.984(0.0093)$ \\
\hline
\end{tabular}

Note: Mackinnon approximate $p$-value in parenthesis

A 2: Best-fitted Model using AIC and BIC

\begin{tabular}{|c|c|c|c|c|c|c|}
\hline Variable & Model & Obs. & II(model) & $\mathrm{df}$ & AIC & $\mathrm{BIC}$ \\
\hline \multirow[t]{2}{*}{ Guns \& Ammunition } & ARIMA $(1,0,1)$ & 101 & -503.36 & 4 & 1014.73 & 1025.19 \\
\hline & ARIMA $(0,0,1)$ & 101 & -503.80 & 3 & 1013.62 & 1021.465 \\
\hline \multirow[t]{2}{*}{ Vehicle Theft } & $\operatorname{ARIMA}(1,0,1)$ & 101 & -441.35 & 4 & 890.72 & 901.18 \\
\hline & ARIMA $(2,0,1)$ & 101 & -440.12 & 5 & 890.25 & 903.33 \\
\hline \multirow[t]{3}{*}{ Drugs } & $\operatorname{ARIMA}(2,0,1)$ & 101 & -729.55 & 5 & 1469.11 & 1482.19 \\
\hline & ARIMA $(1,0,2)$ & 101 & -724.74 & 5 & 1459.49 & 1472.56 \\
\hline & ARIMA $(1,0,1)$ & 101 & -730.51 & 4 & 1469.04 & 1479.50 \\
\hline
\end{tabular}

Note: Best-fitted or Final models are in bold.

\section{Figures}



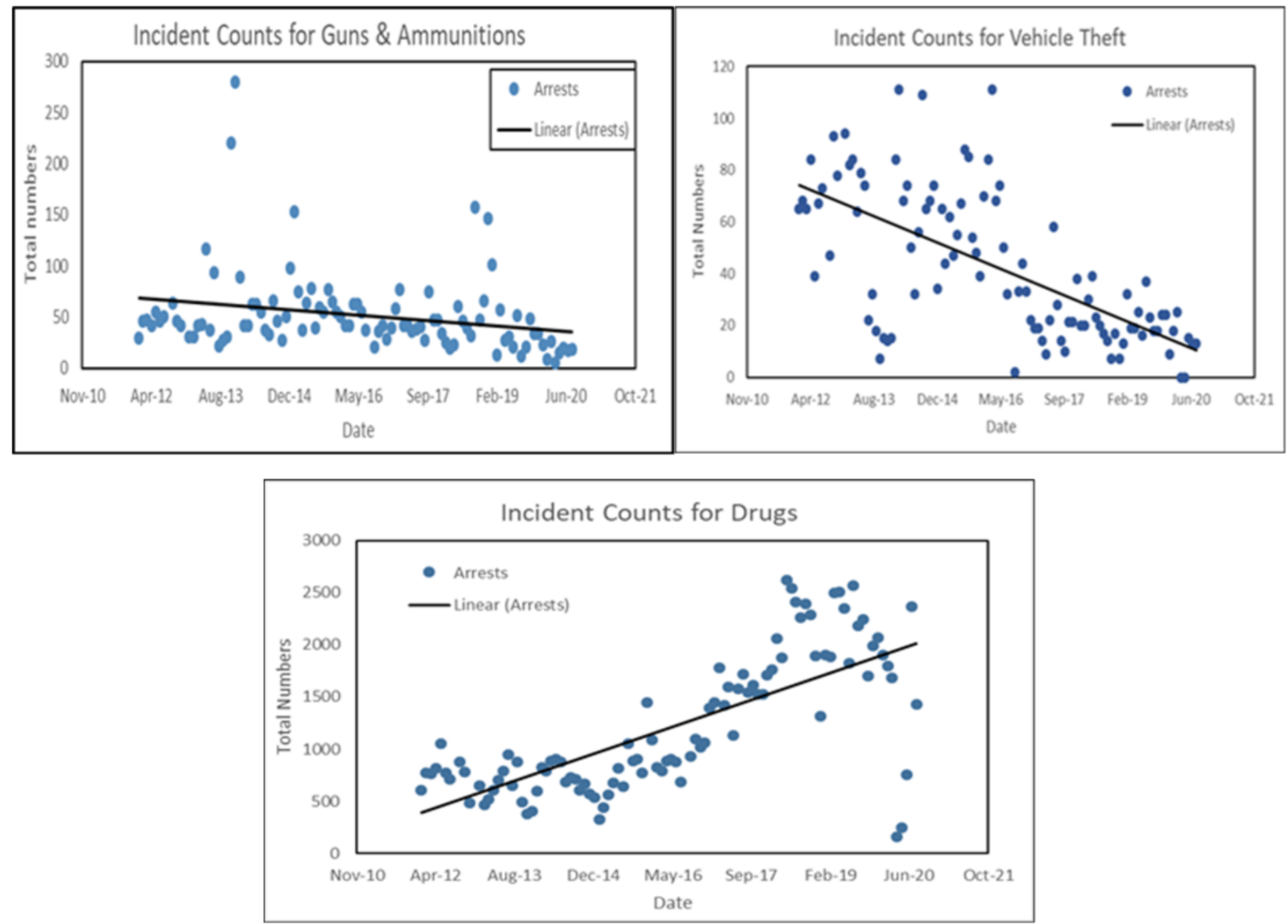

Figure 1

Simple Linear Trend Analysis of the number of Arrests for all Crime Series Data source: Incidence Reports of Dhaka Metropolitan Police (DMP) and author's compilation 

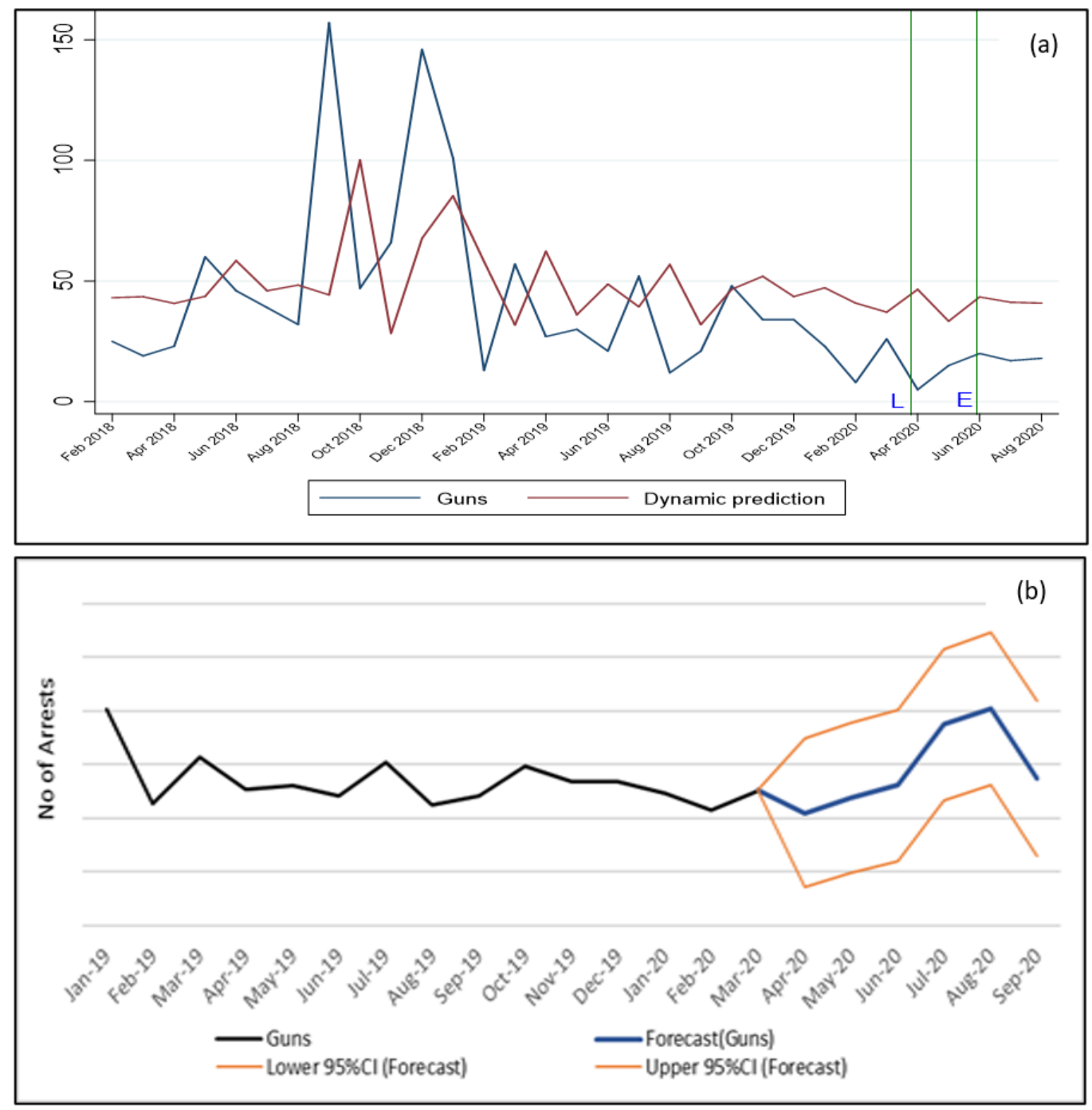

Figure 2

Long term trend and ARIMA forecast of Guns \& Ammunitions Note: Frequency of the number of arrests for illegal arms dealing during coronavirus

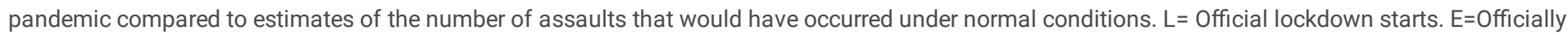
lockdown eased. 


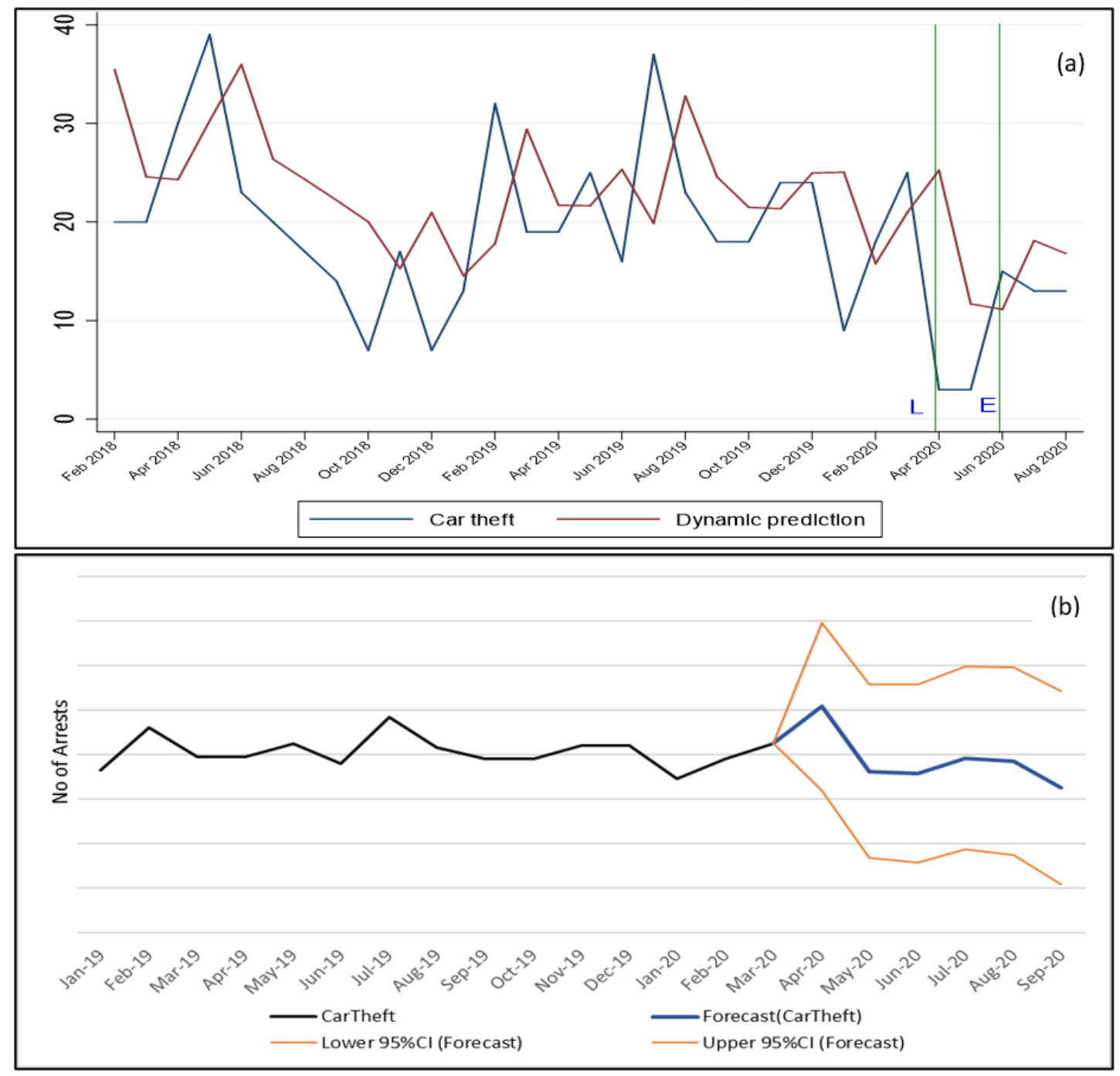

Figure 3

Long term trend and ARIMA forecast of Vehicle Theft Note: Frequency of the number of arrests for vehicle theft dealing during coronavirus pandemic compared to estimates of the number of assaults that would have occurred under normal conditions. $L=$ Official lockdown starts. E=Officially lockdown eased. 


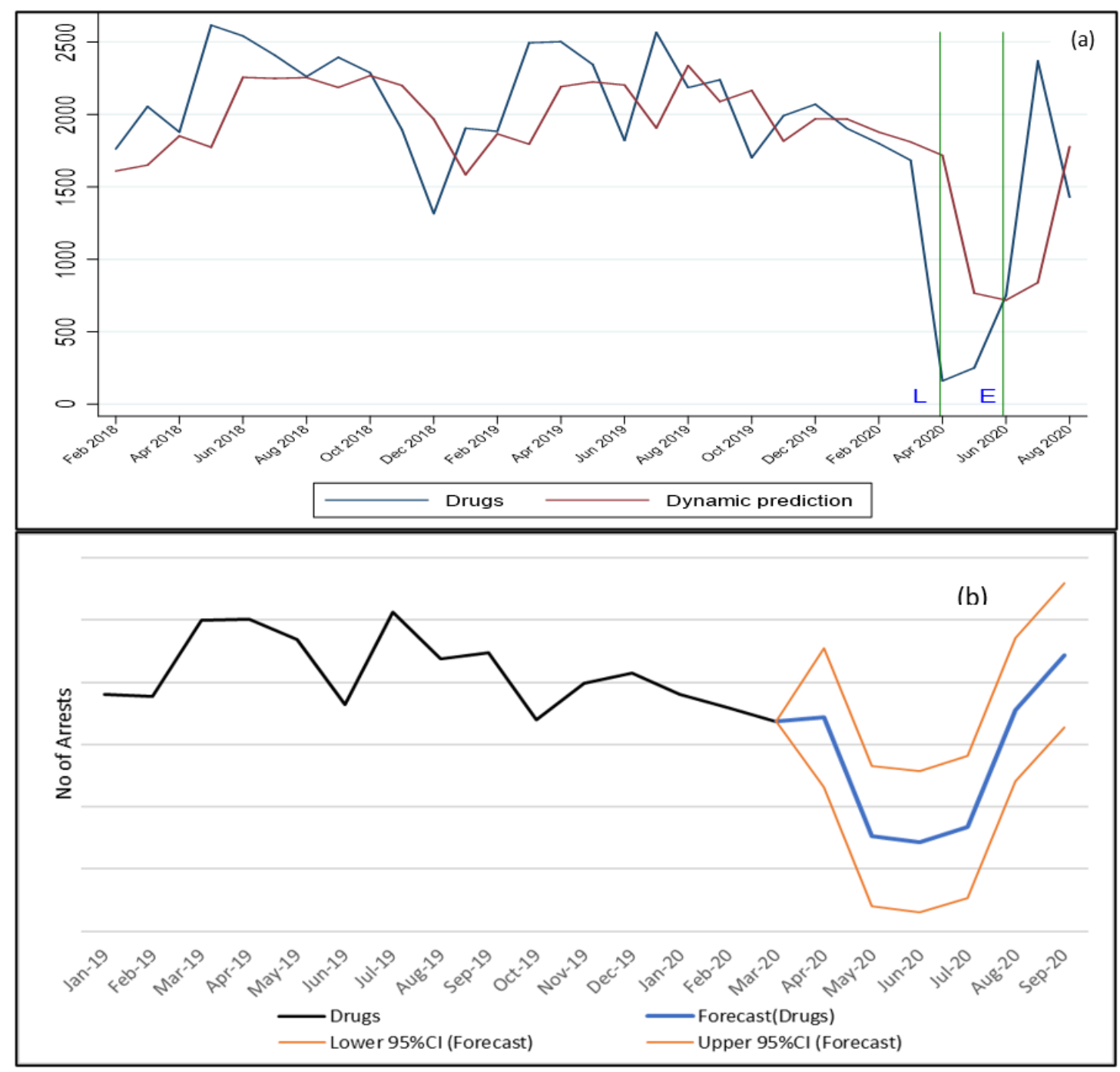

Figure 4

Long term trend and ARIMA forecast for the handling of Drugs Note: Frequency of the number of arrests for illegal arms dealing during coronavirus

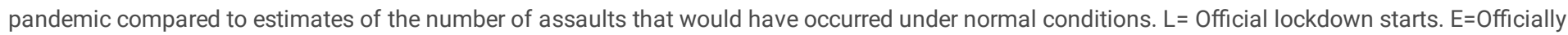
lockdown eased. 